\title{
Thermal Stresses in Adhesively Bonded Joints: Numerical and Analytical Analysis
}

\section{Francesco Marchione}

Department of Construction, Civil Engineering and Architecture (DICEA) Marche Polytechnic University, 60131, Ancona, Italy E-mail: f.marchione@pm.univpm.it

Received: 30 November 2020; Revised: 30 December 2020; Accepted: 9 January 2021

\begin{abstract}
The adhesive technique is observing a considerable increase in applications in various fields. Unlike traditional joining methods, this technology allows the stress peaks and the weight of the resulting structure to be reduced. Adhesive joints during their service life not only undergo mechanical but also thermal stresses. The thermal compatibility between the adhesive and the adherents used is a fundamental aspect to consider in the design phase. This paper reports on and analyses the results obtained from a linear Finite Element Method (FEM) simulation for a hybrid adhesive joint, as the thickness and characteristics of the adhesive layer vary. An analytical solution for adhesivefree joints is presented according to both beam and plate theories. The analytical and numerical results, in case of no adhesive, are in good agreement with good approximation. The introduction of the adhesive layer allows to obtain higher displacement values than in the adhesive-free configuration. The increase in displacement and therefore in ductility confirms the effectiveness of the adhesive joint for real applications.
\end{abstract}

Keywords: thermal stress, adhesives, adhesive joint, thermal analysis, FEM analysis

\section{Nomenclature}

$\begin{array}{ll}\text { DOF } & \text { degrees of freedom } \\ \varepsilon_{i}^{\text {inf }} & \text { thermal strain in the inner adherent } \\ A D H i & \text { i-th adhesive } \\ \varepsilon_{i}^{\text {sup }} & \text { thermal strain in the upper adherent } \\ \rho & \text { density } \\ v & \text { poisson ratio } \\ \alpha & \text { coefficient of thermal expansion } \\ P & \text { thermal load } \\ b & \text { width of the adherents } \\ t & \text { thickness of the adherents } \\ \Delta T & \text { temperature delta } \\ w & \text { vertical displacement } \\ F E M & \text { finite element method }\end{array}$

Copyright (C2021 Francesco Marchione

DOI: https://doi.org/10.37256/est.212021729

This is an open-access article distributed under a CC BY license

(Creative Commons Attribution 4.0 International License)

https://creativecommons.org/licenses/by/4.0/ 


$\begin{array}{ll}U 1 & \text { displacement along } x \text {-axis } \\ U 2 & \text { displacement along } y \text {-axis } \\ \kappa & \text { flexural curvature } \\ M & \text { bending moment } \\ I & \text { moment of inertia } \\ \sigma_{i} & \text { thermal stress } \\ E_{t} & \text { elastic modulus in tension }\end{array}$

\section{Introduction}

The study of stress distribution within the adhesive layer is of increasing interest due to the diffusion of adhesive technology for structural applications and industrial uses (e.g. automotive [1]-[3] and aerospace industry [4]-[6]). The increasing diffusion of adhesive joints is due to its advantages (i.e. more uniform distribution of stresses [7], greater contact area between joined materials [8], possibility of joining different materials [9], [10]). There are numerous studies in the literature aimed at investigating the stress distribution in the adhesive layer. However, one weakness of adhesive technology is the effects of exposure to moisture and high temperatures [11], [12]. In fact, exposure to humid environmental conditions leads to the presence of water, which promotes degradation phenomena on the adhesive [13]. Several models have been proposed to describe the degradation mechanisms of the adhesive joint. In different applications, adhesive joints are subjected to different thermal conditions during their service life. A joint with no degrees of freedom (DOF) constrained and subjected to a uniform thermal change shows uniform thermal deformation. On the other hand, a non-uniform temperature variation results in a non-uniform distribution of deformation due to thermal stress. Thus, an adhesive joint subjected to thermal variation during its service life, exhibits deformation due to both mechanical and thermal stresses [14]. Although the adhesive joint allows different materials to be joined together, it is necessary to consider that adhesives and adherents have different coefficients of thermal expansion. This aspect, accompanied by the combination of mechanical and thermal stresses, is a fundamental point in the evaluation of joint stresses.

Analytical methods are therefore required in the design phase to determine an accurate stress solution for the stress field of the adhesive joints. The first solutions were proposed by Volkersen [15] and by Goland and Reissner [16]. Several more accurate solutions followed, considering the effect of bending moments [17], anisotropic adherents [18], or different configurations of the adhesive joint [19]-[22].

Further predictive models of stress distribution have been proposed by Morgado et al. [23]. Approaches based on elasticity theory have been provided by Timoshenko [24], Yin [25], Chen et al. [26], and Kuo [27].

Timoshenko [24] investigated the general theory of bending of a bi-metal joint subjected to uniform heating. The equations are obtained by calculating temperatures to determine the critical load, deformation during buckling conditions. Yin [25] proposed a variational method with stress functions to determine interlaminar stresses and freeboard effects in a lamellar beam under thermal loads. The stress function in each layer is approximated by a cubic polynomial function of the thickness coordinate. The equilibrium equations, tensile boundary conditions and continuity conditions of the interlaminar stresses satisfied in this analysis, while the compatibility equations and the interfacial continuity of the tangential stresses are applied in the middle direction with the principle of virtual work. Chen et al. [26] considered laminated beams consisting of layers made of different materials fixed together by thin adhesives. The problem is addressed by the theory of two-dimensional elasticity in combination with the energy variability theorem. The calculation of interlaminar stress distributions shows that high stress occurs at the ends of the beam. Kuo [27] studied the problem of the plane stresses of a semi-infinite, bimetallic thermostat, subjected to uniform heating or cooling, treated with the elasticity theory. The solutions to this problem are expressed as the sum of a basic solution for a bimetal strip of infinite length and a series of complementary solutions. This type of elastic theory evaluates the stress field according to complex stress functions. A complete overview of analytical predictive modelling of thermal stresses could be found, for example, in the review authored by Suhir [28]. Xiaoyan et al. [29] proposed a thermal stress analytical model of three-layer bonded structure under temperature field. Thermal stress distribution of bonded structure composed of silicone chip, polyimide film and composite under temperature gradient from -120 to $100{ }^{\circ} \mathrm{C}$ was investigated. Jumbo 
et al. [30] used FEM and continuum mechanics techniques to model the thermal residual stress distribution in bonded joints with 2D methods. The computational methods are used to predict the thermal residual stresses in bonded singlelap joints and double-lap joints. The thermal stresses are found to be highest in hybrid joints. Franco et al. [31] proposed a method to evaluate contact stresses in a bonded joint due to differential thermal expansions. The problem is formulated in terms of Papkovich-Fadle eigenfunctions, which satisfy the boundary conditions. The resulting integral equations are solved with the Jacobi integration formula. The size of the cohesive zone depends upon the length and height of the joint.

The present paper reports on a numerical and analytical linear analysis to evaluate the bending stresses occurring on a hybrid adhesive joint undergoing thermal load. In particular, the analytical solution is developed according to the analysis of the beam and plates elasticity theories. The non-linear effects of the second order are not considered, both because they will be the object of further study and because non-linearities could lead to complex solutions. In fact, the proposed linear analysis allows to simply determine the tensional state of the joint. The results obtained are detailed in the following.

\section{Theoretical analysis}

Changes in temperature may promote thermal deformation in solid body. Hence, the DOFs in a body also affect deformations induced by a temperature change. In fact, in the case of a free body, thermal expansion could occur freely, without the production of internal stresses. In this case, only thermal deformation occurs. In the case of any constrained body, the degrees of constraint influence the deformation of a body in one or more directions. Thermal deformation $\left(\varepsilon_{\text {thermal }}\right)$ is accompanied by mechanical deformation $\left(\varepsilon_{\text {mechanical }}\right)$, due to the presence of the constraints:

$$
\varepsilon_{\text {total }}=\varepsilon_{\text {mechanical }}+\varepsilon_{\text {thermal }}
$$

The following is the case of a hybrid adhesive joint made of steel and glass adherents. The mechanical and physical characteristics of the materials considered are given in Table 1 and 2.

Table 1. Mechanical parameters for steel adherent

\begin{tabular}{cccc}
\hline & STEEL & & \\
\hline $\mathrm{E}_{\mathrm{t}}[\mathrm{GPa}]$ & $\rho\left[\mathrm{N} / \mathrm{m}^{3}\right]$ & $v[-]$ & $\alpha\left[{ }^{\circ} \mathrm{C}^{-1}\right]$ \\
205 & 78000 & 0.30 & $12 \times 10^{-6}$ \\
\hline
\end{tabular}

Table 2. Mechanical parameters for glass adherent

\begin{tabular}{cccc}
\hline \multicolumn{3}{c}{ GLASS } & \\
\hline $\mathrm{E}_{\mathrm{t}}[\mathrm{GPa}]$ & $\rho\left[\mathrm{N} / \mathrm{m}^{3}\right]$ & $v[-]$ & $\alpha\left[{ }^{\circ} \mathrm{C}^{-1}\right]$ \\
75 & 25500 & 0.30 & $23.30 \times 10^{-6}$ \\
\hline
\end{tabular}

The joint considered (Figure 1) is simply supported on the minor edges of the middle plane of the adhesive layer. Figure 2 shows the different levels considered to calculate the stresses on the two adherents. In the following section, stresses and strains observed on the upper and lower surfaces of each adherent layer are determined. 

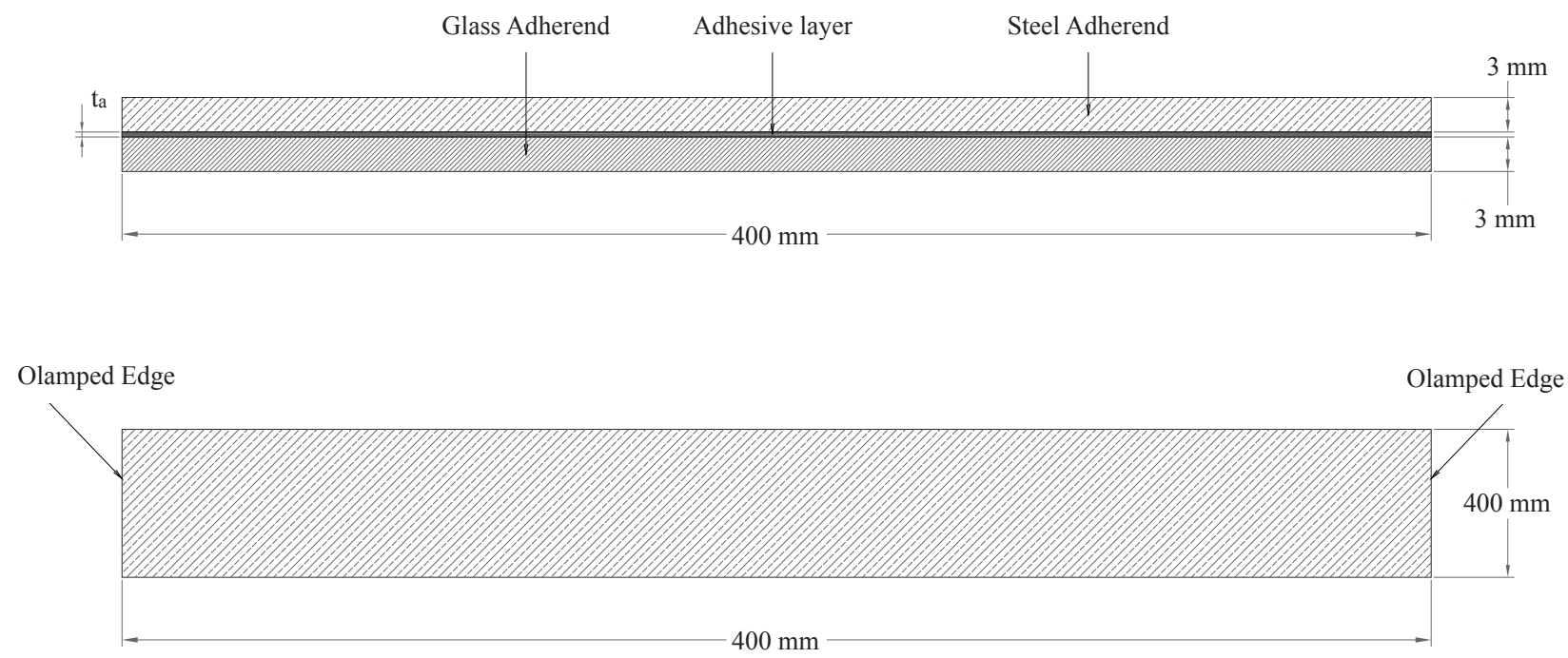

Figure 1. Geometry of the adhesive joint: section and plane views

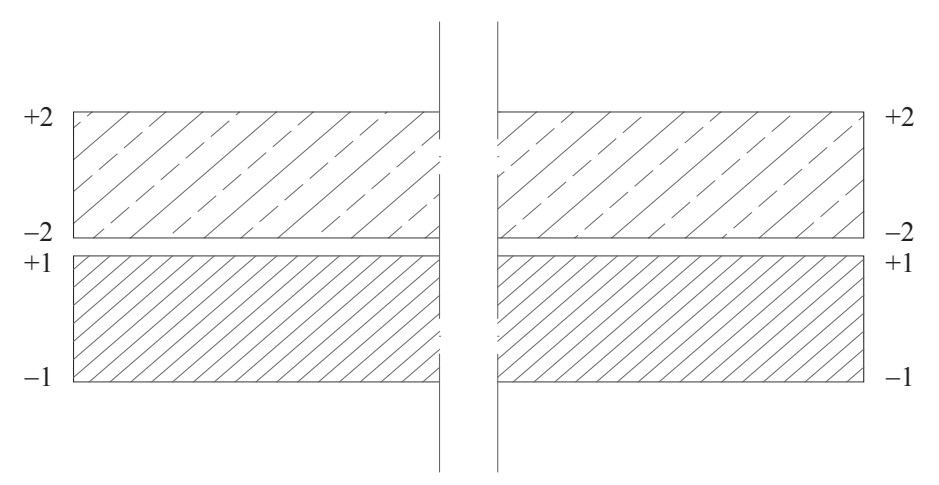

Figure 2. Levels considered in the calculations

\subsection{Beam theory equations}

The adhesive joint shown in Figure 1 is considered. The mechanical characteristics of the materials are shown in the Table 1 and 2.

The dimensions of the joint are: length equal to $400 \mathrm{~mm}$, width equal to $40 \mathrm{~mm}$, and thickness of the adherents equal to $4 \mathrm{~mm}$. A thermal variation of $30^{\circ} \mathrm{C}$ is also considered for the whole body.

The value of the resulting force, the bending moment and the moment of inertia for each adherent could be expressed as follows:

$$
\begin{gathered}
P=\frac{b t^{2}}{12} \kappa\left(E_{1}+E_{2}\right) \\
M_{i}=E_{i} I_{i} \kappa \\
I_{i}=\frac{b t^{3}}{12}
\end{gathered}
$$


Where $\kappa_{1}=\kappa_{2}=\kappa$ represents the curvature for each adherent.

Stresses are then determined at each level:

$$
\begin{gathered}
\sigma_{1}^{\text {inf }}=\frac{P}{b t}-\frac{M_{1} t}{2 I_{1}} \\
\sigma_{1}^{\text {sup }}=\frac{P}{b t}+\frac{M_{1} t}{2 I_{1}} \\
\sigma_{2}^{\text {inf }}=-\frac{P}{b t}-\frac{M_{2} t}{2 I_{2}} \\
\sigma_{2}^{\text {sup }}=-\frac{P}{b t}+\frac{M_{2} t}{2 I_{2}}
\end{gathered}
$$

Consequently, the total strains are:

$$
\begin{aligned}
& \varepsilon_{i}^{\text {sup }}=\alpha_{i} \Delta T+\frac{\sigma_{i}^{\text {sup }}}{E_{i}} \\
& \varepsilon_{i}^{\text {inf }}=\alpha_{i} \Delta T+\frac{\sigma_{i}^{\text {inf }}}{E_{i}}
\end{aligned}
$$

The curvature is expressed by the following:

$$
\kappa=\frac{\left(\alpha_{2}-\alpha_{1}\right) \Delta T}{t} \frac{12 E_{1} E_{2}}{E_{1}^{2}+E_{1}^{2}+14 E_{1} E_{2}}
$$

For the elastic theory of the beam the curvature is given by:

$$
\kappa=\frac{d^{2} w}{d x^{2}}
$$

The maximum flexural displacement could be expressed in this form:

$$
w=\kappa \frac{x}{2}(x-l)
$$

\subsubsection{Beam theory application}

By considering the adhesive joint shown in Figure 1, the mechanical characteristics of the materials are shown in the Table 1 and 2.

The joint has the following dimensions: length equal to $400 \mathrm{~mm}$, width equal to $40 \mathrm{~mm}$, and thickness of the adhesives equal to $4 \mathrm{~mm}$. A thermal variation of $30^{\circ} \mathrm{C}$ is also considered.

The results obtained from the calculation are as follows:

$$
\sigma_{1}^{\text {inf }}=-1.7205 M P a
$$




$$
\begin{gathered}
\sigma_{1}^{\text {sup }}=3.3397 M P a \\
\sigma_{2}^{\text {inf }}=-3.3174 M P a \\
\sigma_{2}^{\text {sup }}=1.5181 M P a
\end{gathered}
$$

Consequently, the total deformations are:

$$
\begin{aligned}
& \varepsilon_{1}^{\text {sup }}=4.4800 \cdot 10^{-5} \\
& \varepsilon_{1}^{\text {inf }}=-2.2670 \cdot 10^{-5} \\
& \varepsilon_{2}^{\text {sup }}=2.2361 \cdot 10^{-5} \\
& \varepsilon_{2}^{\text {inf }}=-4.5109 \cdot 10^{-5}
\end{aligned}
$$

The maximum displacement is equal to:

$$
w=0.449804 m m
$$

\subsection{Plate theory equations}

The plate theory differs from the beam theory since it considers transverse strains and stresses. Stresses in the third direction are neglected.

The plate theory cannot be applied to the edges of the adhesive joint due to approximations in the calculations, but is still valid at a given edge distance, e.g. in the middle of the joint.

The resulting force is given by the following expression:

$$
\begin{gathered}
P=\frac{b t^{2}}{12} \kappa \frac{\left(E_{1}+E_{2}\right)}{1-v} \\
M_{i}=\kappa \frac{E_{i} I_{i}}{1-v} \\
I_{i}=\frac{b t^{3}}{12}
\end{gathered}
$$

Where $\kappa_{1}=\kappa_{2}=\kappa$ represents the curvature for each adherent.

Stresses are determined at each level:

$$
\begin{aligned}
& \sigma_{1}^{\text {inf }}=\frac{P}{b t}-\frac{M_{1} t}{2 I_{1}} \\
& \sigma_{1}^{\text {sup }}=\frac{P}{b t}+\frac{M_{1} t}{2 I_{1}}
\end{aligned}
$$




$$
\begin{aligned}
& \sigma_{2}^{\text {inf }}=-\frac{P}{b t}-\frac{M_{2} t}{2 I_{2}} \\
& \sigma_{2}^{\text {sup }}=-\frac{P}{b t}+\frac{M_{2} t}{2 I_{2}}
\end{aligned}
$$

Consequently, strains are:

$$
\begin{aligned}
& \varepsilon_{i}^{\text {sup }}=\alpha_{i} \Delta T+\frac{\sigma_{i}^{\text {sup }}}{E_{i}}(1-v) \\
& \varepsilon_{i}^{\text {inf }}=\alpha_{i} \Delta T+\frac{\sigma_{i}^{\text {inf }}}{E_{i}}(1-v)
\end{aligned}
$$

The expression of flexural displacement is obtained as follows:

$$
w=\kappa \frac{x}{2}(x-l)+\kappa \frac{y}{2}(y-b)
$$

\subsubsection{Plate theory application}

By considering the adhesive joint shown in Figure 1, the mechanical characteristics and geometry of the materials are considered the same as those used for the previous application. A thermal variation of $30{ }^{\circ} \mathrm{C}$ is again considered.

The results obtained from the calculation are as follows:

$$
\begin{gathered}
\sigma_{1}^{\text {inf }}=-2.4578 M P a \\
\sigma_{1}^{\text {sup }}=4.7711 M P a \\
\sigma_{2}^{\text {inf }}=-4.4819 M P a \\
\sigma_{2}^{\text {sup }}=2.1687 \mathrm{MPa}
\end{gathered}
$$

Consequently, the strains are:

$$
\begin{aligned}
& \varepsilon_{1}^{\text {sup }}=4.4800 \cdot 10^{-5} \\
& \varepsilon_{1}^{\text {inf }}=-2.2670 \cdot 10^{-5} \\
& \varepsilon_{2}^{\text {sup }}=2.2361 \cdot 10^{-5} \\
& \varepsilon_{2}^{\text {inf }}=-4.5109 \cdot 10^{-5}
\end{aligned}
$$

The maximum displacement is equal to: 


\section{Numerical (FEM) analysis}

The numerical simulation is done using the commercial software ANSYS ${ }^{\odot} 19$. Hexahedral elements with eight nodes having three degrees of freedom are used in the FEM analysis. The model geometry was meshed with a base element size of $0.10 \mathrm{~mm}$. A temperature difference of $30^{\circ} \mathrm{C}$ has been set for all solids in the joint. The same boundary conditions have been applied to all the configurations considered. The edges of the middle plane of the adhesive layer have been hinged at one end with the following DOFs: $\mathrm{U} 1=\mathrm{U} 2=0$. For the remaining end, the following DOFs have been set: $\mathrm{U} 2=0$.

\subsection{Joint with no adhesive layer}

The first case considered is the one in which the adherents are coupled without an adhesive layer. The results obtained from the FEM simulation are:

$$
\begin{gathered}
\sigma_{1}^{\text {inf }}=-2.4578 \mathrm{MPa} \\
\sigma_{1}^{\text {sup }}=4.7711 \mathrm{MPa} \\
\sigma_{2}^{\text {inf }}=-4.4819 \mathrm{MPa} \\
\sigma_{2}^{\text {sup }}=2.1687 \mathrm{MPa}
\end{gathered}
$$

Consequently, the total strains are:

$$
\begin{aligned}
& \varepsilon_{1}^{\text {sup }}=4.4800 \cdot 10^{-5} \\
& \varepsilon_{1}^{\text {inf }}=-2.2670 \cdot 10^{-5} \\
& \varepsilon_{2}^{\text {sup }}=2.2361 \cdot 10^{-5} \\
& \varepsilon_{2}^{\text {inf }}=-4.5109 \cdot 10^{-5}
\end{aligned}
$$

The maximum displacement is equal to:

$$
w=0.449829 m m
$$

\subsection{Joint with adhesive layer}

This section considers the influence of the introduction of the adhesive layer between the steel and glass adherents. In particular, the influence of the thickness and elastic modulus of the adhesive on the joint deformation are investigated and analysed. Five different types of commercial structural adhesives with different elastic modulus have been considered. Mechanical characteristics of the adhesives used for the simulation are reported in Table 3. Furthermore, for each type of adhesive, 3 different thickness values were considered (i. e. $0.30,0.60,1.00 \mathrm{~mm}$, respectively). 
Table 3. Mechanical properties of the adhesive considered

\begin{tabular}{cccccc}
\hline Adhesive & ADH 1 & ADH 2 & ADH 3 & ADH 4 & 585 \\
\hline$E_{t}(\mathrm{MPa})$ & 3810 & 3250 & 2280 & 0.40 & 0.40 \\
$v[-]$ & 0.40 & 0.40 & $5.90 \times 10^{-5}$ & $5.90 \times 10^{-5}$ & $5.90 \times 10^{-5}$ \\
$\alpha\left[{ }^{\circ} \mathrm{C}^{-1}\right]$ & $5.90 \times 10^{-5}$ & $5.90 \times 10^{-5}$ \\
\hline
\end{tabular}

Figure 3 to 7 show the results obtained.

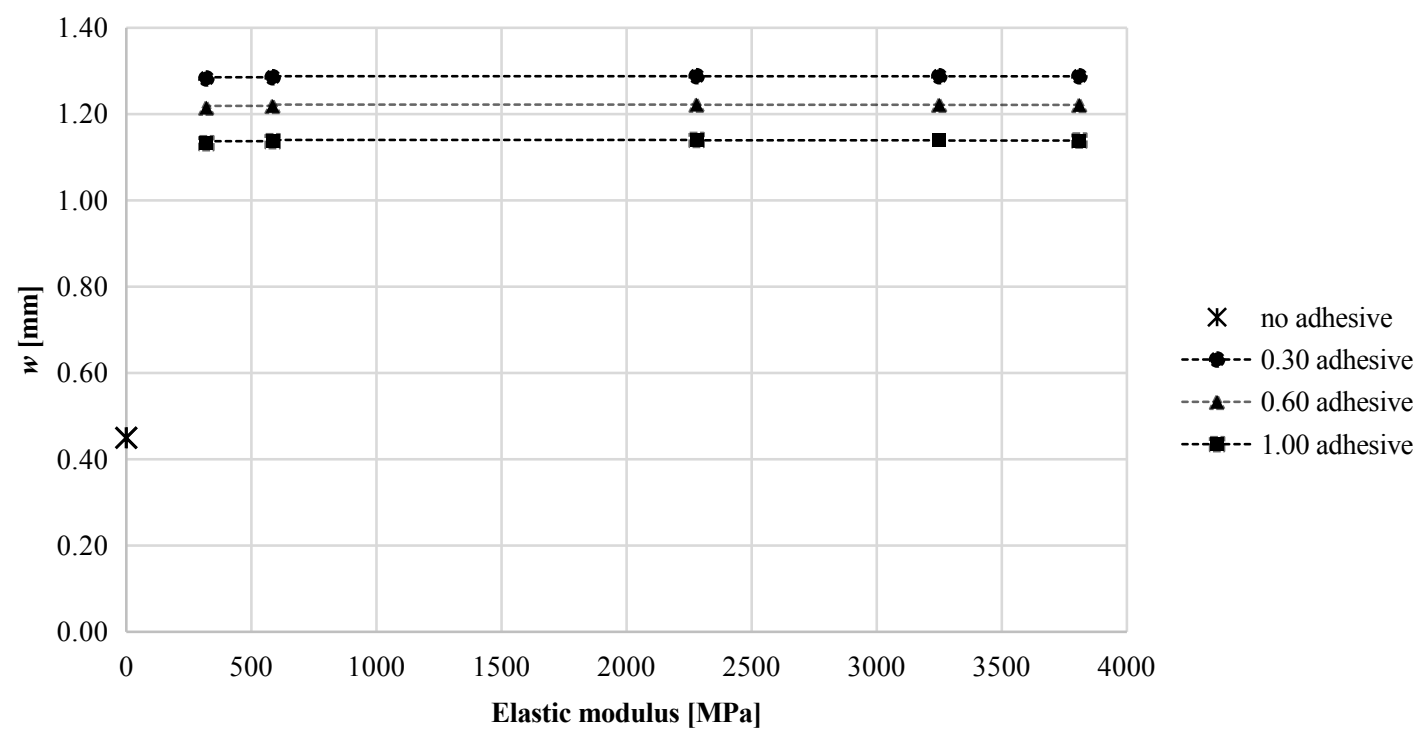

Figure 3. Maximum displacement

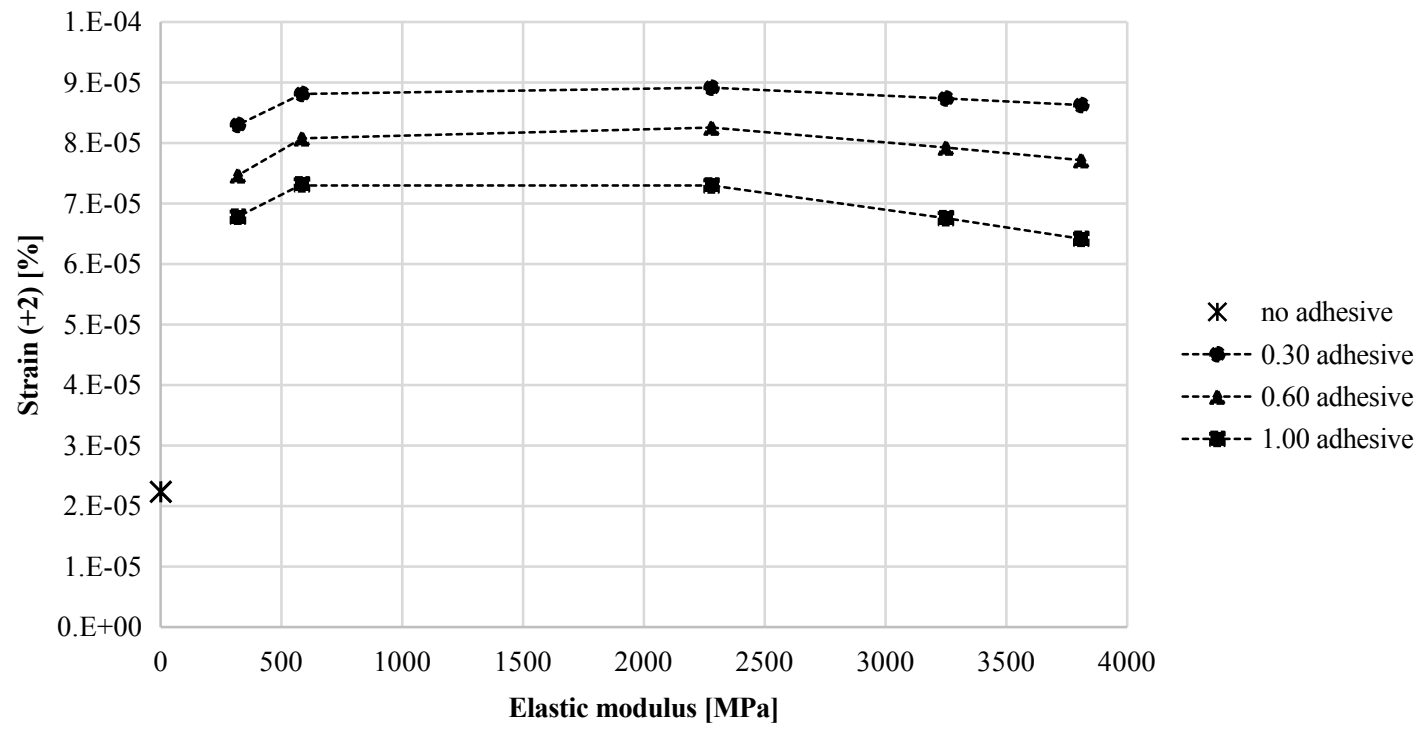

Figure 4. Strain at level +2 


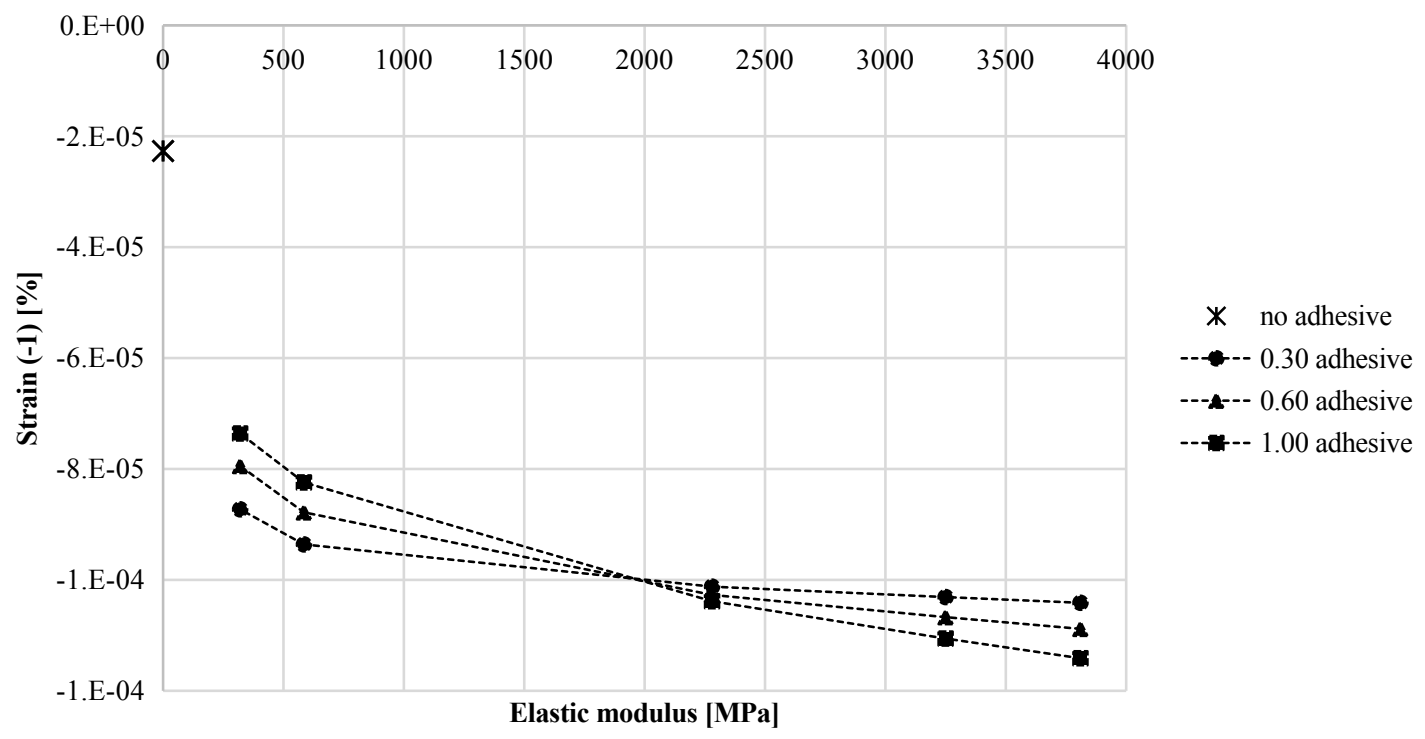

Figure 5. Strain at level -1

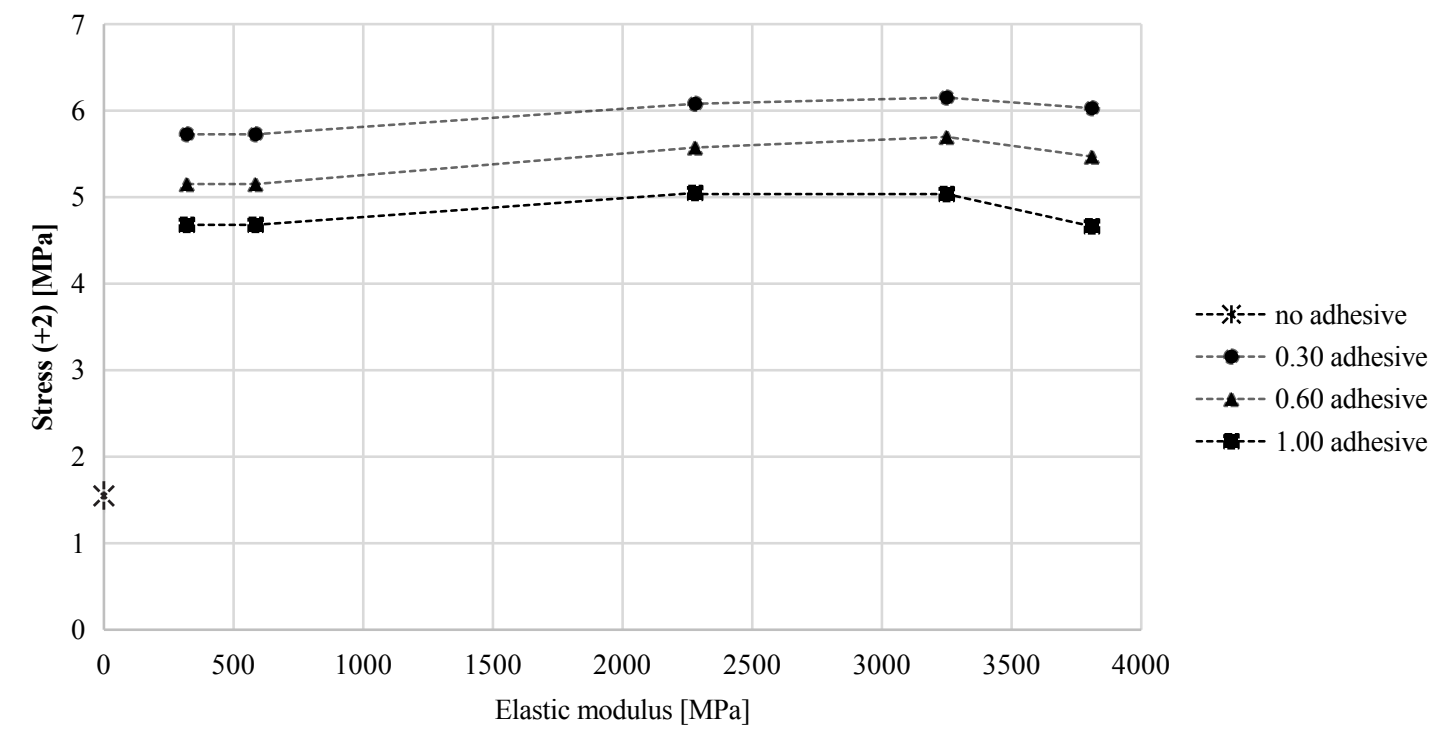

Figure 6. Stress at level +2

In particular, the adhesives considered have the same coefficient of thermal expansion and different elastic moduli. The stiffness of the adhesive varies considerably in the range considered. In fact, it could be observed that ADH1 adhesive is the stiffest, with an elastic modulus typical of epoxy adhesives, while the ADH5 adhesive is the most ductile, with an elastic modulus similar to that of acrylate adhesives. The choice to consider varying elastic moduli is made in order to consider the variety of commercially available adhesives.

The introduction of the adhesive layer induces considerable changes in the stress and strain fields of the joint.

Figure 3 shows the maximum displacements detected in the joint. It could be observed that the introduction of the adhesive layer makes it possible to obtain on average three times greater displacements than without adhesive. Therefore, the evaluation of the displacements according to the elastic theory of the beam-in the absence of adhesiveleads to conclusions in favour of safety. 


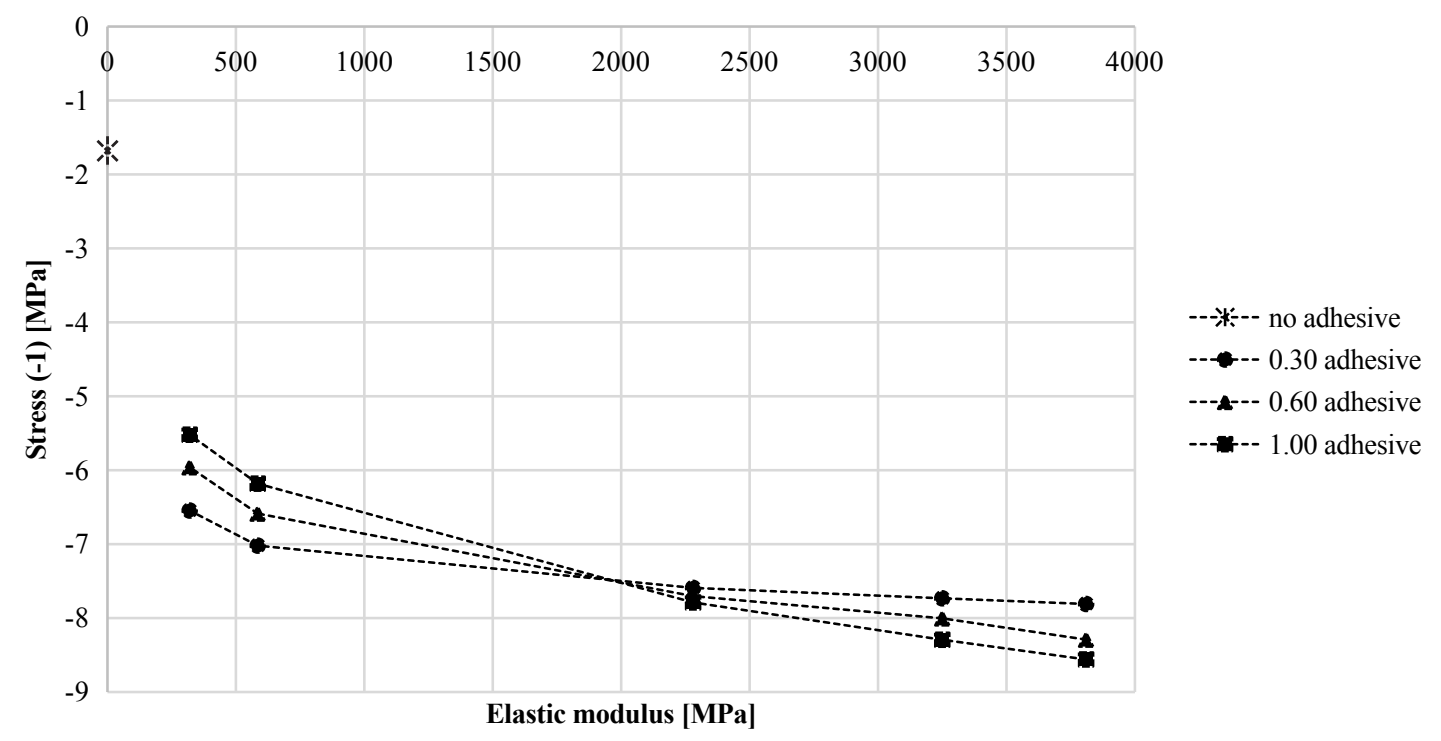

Figure 7. Stress at level -1

Figure 4 to 5 show maximum strains measured at levels +2 and -1 respectively. It could be observed that for level +2 , the strains decrease as the thickness of the adhesive layer increases, regardless of the modulus of elasticity. For level -1 a critic value of the elastic modulus (approx. $2000 \mathrm{MPa}$ ) is observed, which leads to a change in the stress trend. The same trend is observed in the stress distribution, represented respectively in Figure 6 and 7.

\section{Conclusions}

Different analytical and numerical approaches have shown the difference between the tensional and strain fields in an adhesive joint subjected to thermal loads, depending on whether the adhesive layer is present or not, or with different thicknesses.

The main outcomes are:

The analytical model proposed according to the classical plate and beam theory shows good agreement with the results of the numerical simulations;

The illustrated calculation model represents a simple tool for predicting the effect of thermal stress on the composite resulting structure;

Neglecting the presence of the adhesive layer leads to a safe assessment of the magnitude of the displacements and therefore of the measured strains;

The insertion of the adhesive layer allows obtaining a ductile joint, therefore characterised by greater displacements;

A critical value of the elastic modulus of the adhesive is observed (about $2000 \mathrm{~Pa}$ ), so that the different thicknesses of the adhesive layer exhibit a change in the trend of the curves relating to the maximum deformations and stresses measured.

The analytical approach is explanatory of cases where the thickness of the adhesive may be neglected. This case, as could be seen from the obtained results, leads to safety evaluations for maximum displacements and strains measured. The introduction of the adhesive layer enables much higher displacement to be obtained than in the adhesive-free configuration. This makes it possible to absorb higher stress values and thus to realize more ductile joints. The increase in displacement and therefore ductility confirms the effectiveness of the adhesive joint for real applications such as aeronautics, automotive industries, civil engineering. 


\section{Conflict of interest}

The author declares that there is no conflict of interest regarding the publication of this paper.

\section{Reference}

[1] K. Demir, S. Bayramoglu, and S. Akpinar, "The fracture load analysis of different support patches in adhesively bonded single-lap joints," Theoretical and Applied Fracture Mechanics, vol. 108, no. 2, pp. 102653, 2020. Available: doi: 10.1016/j.tafmec.2020.102653.

[2] M. D. Banea, M. Rosioara, R. J. C. C. Carbas, and L. F. M. M. da Silva, "Multi-material adhesive joints for automotive industry," Composites Part B Engineering, vol. 151, no. 6, pp. 71-77, 2018. Available: https://doi. org/10.1016/j.compositesb.2018.06.009.

[3] J. J. M. Machado, P. D. P. Nunes, E. A. S. Marques, and F. M. Lucas, "Adhesive joints using aluminium and CFRP substrates tested at low and high temperatures under quasi-static and impact conditions for the automotive industry," Compososites Part B, vol. 158, no. 5, pp. 102-116, 2019. Available: doi: 10.1016/ j.compositesb.2018.09.067.

[4] P. Hu, X. Han, L. F. M. Da Silva, and W. D. Li, "Strength prediction of adhesively bonded joints under cyclic thermal loading using a cohesive zone model," International Journal of Adhesion and Adhesives, vol. 41, no. 3, pp. 6-15, 2013. Available: doi: 10.1016/j.ijadhadh.2012.10.009.

[5] L. B. Vogelesang and A. Vlot, "Development of fibre metal laminates for advanced aerospace structures," Journal of Materials Processing Technology, vol. 103, no. 1, pp. 1-5, 2000. Available: doi: 10.1016/S0924-0136(00)004118.

[6] E. A. S. Marques, L. F. M. da Silva, and M. Flaviani, "Testing and simulation of mixed adhesive joints for aerospace applications," Compososites Part B Engineering, vol. 74, no. 6, pp. 123-130, 2015. Available: doi: 10.1016/j.compositesb.2015.01.005.

[7] I. Katsivalis, O. Thybo, S. Feih, and M. Achintha, "International journal of adhesion and adhesives development of cohesive zone models for the prediction of damage and failure of glass/steel adhesive joints," International Journal of Adhesion and Adhesives, no. 11, p. 102479, 2019. Available: doi: 10.1016/j.ijadhadh.2019.102479.

[8] F. Marchione, "Investigation of vibration modes of double-lap adhesive Joints: Effect of slot," International Journal of Engineering, vol. 33, no. 10, pp. 1917-1923, 2020. Available: doi: 10.5829/ije.2020.33.10a.10.

[9] N. Keipour, H. R. Valipour, and M. A. Bradford, "Steel-timber composite beam-to-column joints: Effect of connections between timber slabs," International Journal of Engineering, vol. 151, no. 12, pp. 132-145, 2018. Available: doi: 10.1016/j.jcsr.2018.09.019.

[10] M. Giampaoli, V. Terlizzi, M. Rossi, G. Chiappini, and P. Munafò, "Mechanical performances of GFRP-steel specimens bonded with different epoxy adhesives, before and after the aging treatments," Composites Structures, vol. 171, no. 7, pp. 145-157, 2017. Available: doi: https://doi.org/10.1016/j.compstruct.2017.03.020.

[11] G. Qin, J. Na, W. Mu, and W. Tan, "Effect of thermal cycling on the degradation of adhesively bonded CFRP/ aluminum alloy joints for automobiles," International Journal of Adhesion and Adhesives, vol. 95, no. 15, pp. 102439, 2019. Available: doi: 10.1016/j.ijadhadh.2019.102439.

[12] T. Alderucci, M. Rossi, G. Chiappini, and P. Munafò, "Effect of different aging conditions on the shear performance of joints made between GFRP and glass with a UV absorbance coating," International Journal of Adhesion and Adhesives, vol. 94, no. 6, pp. 76-83, 2019. Available: doi: 10.1016/j.ijadhadh.2019.05.009.

[13] S. Aicher and G. Dill-Langer, "Influence of moistuire, temperature and load duration on performance of glued-in rods," Joints in Timber Structures, no. 5, pp. 649, May, 2000. [Online]. Available: https://www.researchgate.net/ publication/277076523_Influence_of_moisture_temperature_and_load_duration_on_performance_of_glued-in_ rods.

[14] N. Stein, P. L. Rosendahl, and W. Becker, "Homogenization of mechanical and thermal stresses in functionally graded adhesive joints," Composites Part B Engineering, vol. 111, pp. 279-293, 2017. Available: doi: 10.1016/ j.compositesb.2016.11.061.

[15] O. Volkersen, "Die Nietkraftverteilung in Zugbeanspruchten Nietverbindungen mit Konstanten Laschenquerschnitten [The rivet load distribution in lap-joints with members of constant thickness subjected to tension]", Luftfahrtforschung, vol. 15, pp. 41-48, 1938.

[16] M. Goland and E. Reissner, "Stresses in cemented joints," Journal of Applied Mechanics, vol. 66, pp. A17, 1944. 
[17] L. J. Hart-Smith, “Adhesive-Bonded Double Lap Joints,” Langley Research Center, Hampton, Virginia, USA, Tech. Report. NASA CR 112235, 1 Jan., 1973.

[18] F. Delale, F. Erdogan, and M. N. Aydinoglu, "Stresses in adhesively bonded joints: A closed-form solution," Journal of Composite Materials, vol. 15, no. 3, pp. 249-271, 1981. Available: doi: 10.1177/002199838101500305.

[19] D. A. Bigwood and A. D. Crocombe, "Elastic analysis and engineering design formulae for bonded joints," International Journal of Adhesion and Adhesives, vol. 9, no. 4, pp. 229-242, 1989. Available: doi: 10.1016/01437496(89)90066-3.

[20] R. D. Adams and N. A. Peppiatt, "Effect of poisson's ratio strains in adherends on stresses of an idealized lap joint," The Journal of Strain Analysis for Engineering Design, vol. 8, no. 2, pp. 134-139, 1973. Available: doi: 10.1243/03093247V082134.

[21] R. D. Adams and N. A. Peppiatt, "Stress analysis of adhesive-bonded lap joints," The Journal of Strain Analysis for Engineering Design, vol. 9, no. 3, pp. 185-196, 1974. Available: doi: 10.1243/03093247V093185.

[22] F. Marchione, "International journal of adhesion and adhesives stress distribution in double-lap adhesive joints: Effect of adherend reinforcement layer," International Journal of Adhesion and Adhesives, vol. 105, no. 11, pp. 102780, 2021. Available: doi: 10.1016/j.ijadhadh.2020.102780.

[23] E. A. S. S. Marques, L. F. M. M. da Silva, M. D. Banea, and R. J. C. C. Carbas, “Adhesive joints for low-and high-temperature use: An overview," The Journal of Adhesion, vol. 91, no. 7, pp. 556-585, 2015. Available: doi: 10.1080/00218464.2014.943395.

[24] S. Timoshenko, "Analysis of bi-metal thermostats," Journal of the Optical Society of America, vol. 11, no. 3, p. 233, 1925. Available: doi: 10.1364/JOSA.11.000233.

[25] W.-L. Yin, "Thermal stresses and free-edge effects in laminated beams: A variational approach using stress functions," Journal of Electronic Packaging, vol. 113, no. 1, pp. 68-75, 1991. Available: doi: 10.1115/1.2905369.

[26] D. Chen, S. Cheng, and T. D. Gerhardt, "Thermal stresses in laminated beams," Journal of Thermal Stresses, vol. 5, no. 1, pp. 67-84, 1982. Available: doi: 10.1080/01495738208942136.

[27] A.-Y. Kuo, "Thermal stresses at the edge of a bimetallic thermostat," Journal of Applied Mechanics, vol. 56, no. 3, pp. 585-589, 1989. Available: doi: 10.1115/1.3176131.

[28] E. Suhir, "Predictive analytical thermal stress modeling in electronics and photonics," Applied Mechanics Review, vol. 62, no. 4, pp. 1-20, 2009. Available: doi: 10.1115/1.3077136.

[29] W. Xiaoyan and Z. Shuang, "Analytical model of thermal stress distribution of bonded structure under temperature field," International Journal of Adhesion and Adhesives, vol. 31, no. 6, pp. 398-401, 2011. Available: doi: 10.1016/ j.ijadhadh.2011.03.005.

[30] F. S. Jumbo, I. A. Ashcroft, A. D. Crocombe, and M. A. Wahab, "Thermal residual stress analysis of epoxy bimaterial laminates and bonded joints," International Journal of Adhesion and Adhesives, vol. 30, no. 7, pp. 523538, 2010. Available: doi: 10.1016/j.ijadhadh.2010.03.009.

[31] A. Franco and G. Royer-Carfagni, "Contact stresses in adhesive joints due to differential thermal expansion with the adherends," International Journal of Solids and Structures, vol. 87, no. 6, pp. 26-38, 2016. Available: doi: 10.1016/j.ijsolstr.2016.02.036. 